\title{
El Ser-para-la-muerte (Das Sein zum Tode) como fundante de una ética en Heidegger
}

\author{
Ulises Salomón Amaya Pérez ${ }^{1}$
}

Recibido en diciembre de 2014, aceptado en marzo de 2015.

“La muerte está atornillada a la vida Los astros se alejan en el infinito y los barcos en el mar

Las voces se alejan en el aire vuelto hacia la nada Los rostros se alejan entre los pinos de la memoria Y cuando el vacío está vacío bajo el aspecto irreparable El viento abre los ojos de los ciegos (...)"

Vicente Huidobro

\begin{abstract}
Resumen
el presente artículo tiene la pretensión de mostrar la posibilidad de una ética en Heidegger a partir del ser-para-la-muerte. Para ello, lo hemos dividido en tres partes. La primera de ellas trata de mostrar el vínculo que existe entre el estar-en-el-mundo y la ética, partiendo de la comprensión que Heidegger tiene de ésta. En el segundo apartado hacemos una aproximación a la cotidianidad del Dasein, señalando algunas implicaciones que esta cotidianidad tiene con claras resonancias éticas. Para finalizar, en el último apartado, tratamos de mostrar cómo el ser-para-la-muerte puede llegar a ser considerado como un fundante ético.
\end{abstract}

\section{Palabras claves}

Estar-en-el-mundo, ser-para-la-muerte, vivencia, cotidianidad, Das man, ética originaria.

\section{Abstract}

This article aims to demonstrate the possibility of a heideggerian ethic beginning with the being-toward-death. To this end, we have divided it in three sections. The first of these attempts to show the relationship that exists between being-in-the-world and ethics, starting from Heidegger's understanding of this. In the second section, we take an approach to

1. Lic. en Filosofía por la Universidad Centroamericana “José Simeón Cañas", El Salvador, Dr. (c) por la Pontificia Universidad Católica de Valparaíso (PUCV), Chile. "Beneficiario Beca Postgrado PUCV 2015”. E-mail: ulises.amaya.p@mail.pucv.cl 
the everydayness of Dasein, indicating some of the implications of this everydayness with clear ethical repercussions. Finally, in the last section, we attempt to show how being-toward-death can come to be considered as a founding ethic.

\section{Keywords:}

being-in-the world, being-toward-death, experience, everydayness, The One, original ethics.

\section{Introducción}

Este trabajo tiene la pretensión de realizar una aproximación a un posible punto de partida para el abordaje ético del pensamiento heideggeriano. Aunque el punto de partida que proponemos, o más bien, el fundante de una posible ética se encuentra en el primer Heidegger, asumimos una continuidad entre aquello que los especialistas han llamado 'el primer y segundo Heidgger'. ${ }^{2}$ Por ello, aunque el fundante ético se encuentre en el desarrollo de SuZ ${ }^{3}$ publicado en 1927, sus resonancias alcanzarán el despliegue posterior a esta época.

Dicho lo anterior debemos iniciar refiriendo la dificultad que implica hablar de una ética en Heidegger. Probablemente la principal razón sean sus propias actuaciones políticas, al menos para muchos de sus críticos, ya que son ellas las primeras en descalificar la posibilidad de construir un planteamiento ético

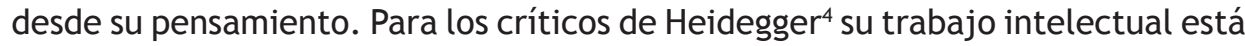
atravesado por sus creencias políticas, su vinculación al nacional socialismo y el hecho de que Heideggger nunca se retractara de su pertenencia al Partido, lo hacen, para muchos, un autor carente de ética, e inclusive, de "humanidad",

2. En este punto optamos por la lectura que realiza von Herrmann, para quien la obra heideggeriana constituye un todo unitario. Basta recordar que en 1962 el mismo Martin Heidegger comenta en el prólogo a la obra del sacerdote jesuita, William Richardson, Trought Phenomenology to Thought de 1963, que la maduración de un complejo temático (Sachverhalt) a través de un largo tiempo fue lo que produjo la Kehre, además, en el Protokoll zu einem Seminar über den Vortrag "Zeit und Sein" del 1962, Heidegger afirma que aquello que constituye la estructura esencial del Ereignis han sido elaborados entre 1935 y 1936. F.W. von Herrmann en 1991 al interpretar la Kehere como la estructura misma del acaecer inicia una nueva linea de comprensión del pensamiento heideggeriano, así, abre una nueva lectura de la obra heideggeriana como un todo unitario. Cfr. Basso Monteverde, Mercedes Leticia, Génesis y constitución del Ereignis, un estudio de la continuidad de la obra de Martin Heidegger, [1919-1939] a través del problema de la diferencia ontológica, Tesis para optar al grado de Doctora en Filosofía, UBA, Argentina, 2013, pp.5-6. En Brief über den "Humanismus"de 1946, traducción de Helena Cortés y Arturo Leyte (Alianza Editorial, Madrid 2000), Heidegger nos dice, "La conferencia 'De la esencia de la verdad', que fue pensada y pronunciada en 1930 pero que no se publicó hasta 1943, permite obtener cierta visión del pensar del giro que se produce en Ser y Tiempo a 'Tiempo y Ser'. Dicho giro no consiste en un cambio del punto de vista de Ser y Tiempo, sino que en él es donde ese pensar que se trataba de obtener llega por vez primera a la dimensión desde la que se ha experimentado Ser y Tiempo, concretamente como experiencia fundamental del olvido del ser".

3. Usaremos "SuZ" para referirnos a la obra Ser y Tiempo de 1927 de Martin Heidegger.

4. Entre quienes podemos mencionar a Víctor Farías, Heidegger y el Nazismo y Emmanuel Faye, Heidegger, l'introduction du nazisme dans la philosophie: autour des séminaires inédits de 1933-1935. 
cosa que según sus críticos, puede apreciarse en su filosofía y es a lo que Heidegger intentará responder en Brief über den Humanismus de 1946.

Para otros, la imposibilidad radica en las aseveraciones del propio autor. Para ellos, Heidegger cierra la posibilidad de esbozar cualquier tipo de ética. Sin embargo, en el presente trabajo trataremos de clarificar en la medida de lo posible a qué se refiere Heidegger con esta supuesta negación de una ética, y además, trataremos de proponer el ser-para-la-muerte (Das Sein zum Tode) como fundante de un planteamiento ético en Heidegger.

"La ética aparece por primera vez junto a la lógica y la física en la escuela de Platón"5. Señala nuestro autor que antes no había una separación en disciplinas, no había, por decirlo así, una parcelación del pensamiento. "Los pensadores anteriores a esa época no conocen ni una ética, ni una lógica, ni una física. Y, sin embargo, su pensar no es ni ilógico ni amoral". ${ }^{6}$ Para Heidegger, en los presocráticos la ética forma parte de una experiencia originaria que no ha caído bajo la nominalización, con esto me refiero a la sustantivación de la acción del pensar en diferentes nombres, por lo que se trataría de un pensar originario, y la ética, al formar parte de ese pensar, sería una ética originaria.

Así, este trabajo busca proponer una veta de lectura del pensamiento heideggeriano y su relación con la ética y sumarse a la investigación que se ha venido realizando en torno a esta temática, véase, por ejemplo: “Ética originaria y la psiquitría" (2006), del profesor Jorge Acevedo de la Universidad de Chile, publicado en Observaciones Filosóficas; “¿Es posible aún una ética? Heidegger y la filosofía práctica” (2004) de Franco Volpi de la Universidad de Padua, publicado en Konvergencias, Filosofía y Culturas en Diálogo. Es relevante señalar lo sugerente de la relación que, en el artículo recién mencionado, propone Volpi entre la Ética Nicomaquea de Aristóteles y lo dicho en Sein und Zeit por Heidegger; “La ética del 'otro comienzo' de Martin Heidegger” (2004) de Luis César Santiesteban Baca, México, publicado en Diánoia; “El problema de la ética en la filosofía de Heidegger" (2012) de Jesús Valera Enríquez, tesis publicada en Dialnet. Así, el estudio de una ética en Heidegger es una investigación vasta y compleja, investigación que se ha complejizado más con la publicación de los Cuadernos Negros, de los cuales tres volúmenes fueron ya publicados por la editorial Vittorio Klostermann en el 2014; esto, según algunos, debido al claro posicionamiento de nuestro autor con respecto a la

5. Heidegger, Martin, “Carta sobre el Humanismo”, visto en, http://www.sandamaso.es/uploaded_ files/3_heidegger_carta_sobre_el_humanismo.pdf, p.17. "Die 'Ethik' kommt mit der 'Logik' und der 'Physik' zum ersten Mal in der Schule Piatons auf”. Heidegger, Martin, Brief über den Humanismus, Wegmarken, ed. F.-W von Herrmann, Vittorio Klosterman, Frankfurt am Main, 1976, pp. 313-364 de la edición de obras completas de Heidegger (Heidegger Gesamtausgabe) visto en: http: //www. sandamaso.es/uploaded_files/3_heidegger_carta_sobre_el_humanismo.pdf p.16.

6. Ibid. “Die Denker vor dieser Zeit kennen weder eine 'Logik'; noch eine 'Ethik', noch die 'Physik'. Dennoch ist ihr Denken weder unlogisch, noch unmoralisch". Ibid. p17. 
temática judía. No es la intención de este artículo entrar a la discusión sobre la presencia del antisemitismo o no en el pensamiento heideggeriano: se trata de una discusión importante sin duda, pero que genera el riesgo de perdernos en una vorágine de posicionamientos, la mayoría de veces, poco objetivos o defensores a ultranza, por lo que optamos por dejar esta discusión para otro lugar. Dicho lo anterior, la novedad de nuestra propuesta es el establecimiento del ser-para-la-muerte (Das Sein zum Tode) como principio de una ética en el pensamiento heideggeriano. No buscamos el desarrollo de esa ética porque éste sobrepasa la pretensión de este trabajo. Nuestra pretensión es dejar señalada la posibilidad de la construcción de esa ética para una futura investigación.

Dentro de los diferentes tratamientos de una ética dentro del corpus heideggeriano, podemos encontrar aquellos que se posicionan en el segundo Heidegger, como es el caso del profesor Acevedo y otros. En este sentido el profesor Acevedo nos dice:

“...según lo señalado hasta ahora, el hombre habita - dicho en breve-, en la verdad del ser, en el claro del ser (Lichtung des Seins). La conferencia "El final de la Filosofía y la tarea del pensar", recién citada, vincula el claro con la Alétheia, el no-ocultamiento (Unverborgenheit). Y, a su vez, la Alétheia con la Léthe -el ocultamiento. Sugiere Heidegger, en efecto, que 'el ocultarse, el ocultamiento (Verborgenheit), la Léthe, pertenece a la Alétheia, no como un mero añadido, como las sombras a la luz, sino como corazón de la Alétheia... A partir de eso, podemos inferir que el hombre mora o habita en la Alétheia y en la Léthe, en el no-ocultamiento y ocultamiento, se entiende, del ser". ${ }^{7}$

Y otro grupo, cuyo mayor representante, nos parece, es el profesor Volpi, ponen mayor énfasis en la presencia aristotélica en el desarrollo del pensamiento de Heidegger, al menos, el Heidegger de Sein und Zeit, y para quien la lectura de nuestro autor reactiva y transforma el sentido de algunos elementos fundamentales de la Ética Nicomaquea. Al respecto, el profesor Volpi señala:

“...Heidegger descubre en Aristóteles una fenomenología de la vida más rica y más originaria que la desarrollada por Husserl, en cuanto considera los tres principales movimientos descubridores de la vida: la póieses, la praxis, la teoría y las tres correspondientes disposiciones: la techné, la phrónesis y la sophia". ${ }^{8}$

Y continúa:

7. Acevedo Guerra, Jorge, “Ética originaria y la psiquiatría”, en, Observaciones Filosóficas, Revista Digital, $N^{\circ} 2$ 2, 2006, visto en, http://www.observacionesfilosoficas.net/eticaoriginaria.html

8. Volpi, Franco, “¿Es posible aún una ética? Heidegger y la Filosofía práctica”, en, Konvergencias, Filosofía y Culturas en Diálogo, Número 7, Año III, Agosto/Septiembre, Argentina, 2004. Visto en, http://www.konvergencias.net/volpi.htm 


\begin{abstract}
"La primera correspondencia, tan evidente que casi no tiene necesidad de ser probada, es la que se da entre los tres modos fundamentales de ser distinguidos y definidos por Heidegger en el curso de los años veinte y en Ser y Tiempo, es decir, Dasein, la Zunhandenheit, y la Vorhandenheit, y las tres determinaciones aristotélicas de la praxis, de la póiesis y de la theoría".9
\end{abstract}

Desde nuestra lectura el ser-para-la-muerte (Das Sein zum Tode) es fundamental, ya que permite salir al hombre de impropiedad (Uneigentlichkeit) y 'despertar' a la propiedad (Eigentlichkeit), sin embargo, este estar vuelto hacia el fin (Sein zum Ende) no implica que el Dasein una vez vuelto hacia la conciencia ${ }^{10}$ de la muerte exista en propiedad (Eigentlichkeit). El Dasein posee una estructura bidimensional ${ }^{11}$, es decir, los modos existenciales de estar-en-el-mundo ${ }^{12}$ (In-derWelt-sein): la propiedad (Eigentlichkeit), y la impropiedad (Uneigentlichkeit) son constitutivos de él y existe cotidianamente en un movimiento entre uno y otro, es decir, entre la caída (Verfallen) y su más propio poder-ser (Sein-können). El ser-para-la-muerte (Das Sein zum Tode) posibilita dicho movimiento, de no ser así, el Dasein existiría solamente en la impropiedad, así, nos parece, la muerte es un fundante, aunque parezca paradójico, no de muerte, sino de vida. El ser-para-la-muerte (Das sein zum Tode) manifiesta la preocupación heideggeriana por volver la filosofía al mundo de la vida, en este sentido es interesante lo que Modesto Berciano nos dice: "Heidegger entiende desde un principio la fenomenología como un nuevo modo de filosofar; como un modo apto para una filosofía devuelta a su lugar propio y originario, el mundo de la vida, y capaz también, según él, de llevar a la expresión la experiencia originaria y las vivencias del mundo de la vida"13. Heidegger se acerca así,

\footnotetext{
9. Ibídem.

10. Para Heidegger la conciencia es fundamental para la aperturidad del Dasein y se encuentra estrechamente relacionado con su carácter fáctico. Nuestro filósofo nos dice en SuZ, "La conciencia da a entender 'algo', la conciencia abre. De esta caracterización formal surge la indicación de remitir este fenómeno a la aperturidad del Dasein"."Das Gewissen gibt »etwas « zu verstehen, es erschließt. Aus dieser formalen Charakteristik entspringt die Anweisung, das Phänomen in die Erslossenheit des Daseins zurückzunehmen".

11. Cuando Heidegger utiliza el concepto de dimensión para referirse al movimiento vital-existencialafectivo del Dasein debe ser comprendido como una distensión, esto significa que existe cierto vínculo entre lo existencial y afectivo, pero ese vínculo, además, refleja una tensión entre ambos. Es a partir de este movimiento que el Dasein se acerca o se aleja de sí mismo en la comprensión del Ser, dicho movimiento arroja al Dasein a los dos modos de ser-en-el-mundo, a saber, el de propiedad e impropiedad.

12. Jorge Eduardo Rivera sostiene que ha solido traducirse In-der-Welt-sein como ser-en-el-mundo, sin embargo, dicha traducción no mostraría, sostiene Rivera, el acto mismo de ser sino que haría referencia a algo quiditativo, por ello, él prefiere la traducción de estar-en-el-mundo porque esta traducción estaría más en consonancia con el carácter ejecutivo del Dasein puesto que remitiría a su carácter existencial-ontológico, además, y esto es relevante, para Rivera, estar-en-el-mundo no expresaría un estar colocado, sino más bien, una acción progresiva que bien podría expresarse en gerundio, estar-siendo-el-mundo, lo que implicaría, la idea de habitar, idea que será fundamental para el Heidegger posterior a los Beiträge zur Philosophie.

13. Villalibre, Modesto Berciano, La revolución filosófica de Martin Heidegger, Editorial Biblioteca Nueva, Madrid, 2001, p. 13.
} 
desde nuestra perspectiva, a cierto tipo de vitalismo, uno bastante próximo al vitalismo nietzscheano. Recordemos que el vitalismo de Nietzsche pasa por la negación de la razón y la vuelta a los instintos y pasiones. Para él son estos últimos los que constituyen una profundización del humanismo. De allí que se afirme que su vitalismo es un naturalismo vitalista que implica la asunción de la inutilidad de la razón y lo divino, y ante ésta, no queda más, para Nietzsche, que buscar cierto asidero en lo natural, criticando así, todos aquellos valores que atenten, según él, contra la naturaleza del ser humano.

Heidegger por su lado, rechaza también esa confianza ciega en la razón y ese recurso a lo divino para justificar las acciones humanas y descargar la responsabilidad moral de éstas. En el despliegue del pensamiento del filósofo de la selva negra, la problemática de la trascendencia ya está presente en Sein und Zeit; pero es en Vom Wesen des Grundes de 1929 que ésta, es decir, la trascendencia, se convierte en un tema fundamental de la reflexión heideggeriana; pero, ¿qué debemos entender cómo tal? La trascendencia, nos dice Heidegger, significa sobrepasamiento (Überstieg) y manifiesta un acontecimiento constitutivo del Dasein. Este sobrepasamiento (Überstieg) es un sobrepasar (übersteigen) desde algo a algo, este movimiento se encuentra estrechamente relacionado con la bidimensionalidad del Dasein. Éste, al sobrepasar aquel ente que comparece ante él, se sobrepasa a sí mismo. ${ }^{14} \mathrm{La}$ trascendencia del Dasein está determinada por su estar-en-el-mundo (In-derWelt-sein), y este acontecimiento, la trascendencia, está relacionado con su carácter ex-céntrico, esto significa que tiene su centro fuera, el Dasein está volcado, radicalmente, hacia fuera. Así, en Heidegger el Dasein habita volcado, o como él mismo dice, en condición de arrojado (Geworfenheit) al mundo (Welt). La ética para el mago de Messkirch es un habitar (Whonen), y este no es de cualquier manera, sino que es un habitar protegiente.

\section{La ética como un estar en el mundo (In-der-Welt-sein)}

"Una sentencia de Heráclito, que sólo tiene tres palabras, dice algo tan simple que en ella se revela inmediatamente la esencia del ethos. Dicha sentencia de

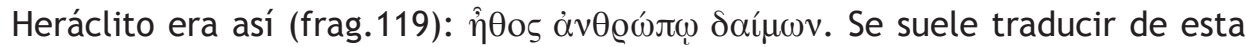
manera: «Su carácter es para el hombre su demonio». Esta traducción piensa en términos modernos, pero no griegos. El término $\hat{\eta} \theta$ os significa estancia, lugar donde se mora. La palabra nombra el ámbito abierto donde mora el hombre. Lo abierto de su estancia deja aparecer lo que le viene reservado a la esencia del hombre y en su venida se detiene en su proximidad". ${ }^{15}$ Así, "El sentido

14. Cfr., Di Sivestre, Carlos, "La temporeidad extático-horizontal como origen de la trascendencia del Dasein”, en, Discusiones Filosóficas, Año 11 № 17, julio-diciembre, Colombia, 2010, pp. 255273, para la cita p. 257.

15. Ibid, p.17. "Ein Spruch des Heraklit, der nur aus drei Wortern besteht, sagt so Einfaches, dass aus ihm das Wesen des Ethos unmittelbar ans Licht Kommt. Der Sprucht des Heraklit lautet (Frgm. 119): $\hat{\eta} \theta 0 \varsigma \alpha \dot{\alpha} v \Theta \varrho \omega \tau \omega \delta \alpha i ́ \mu \omega v$. Man pflegt allgemein zu übersetzen: «Seine Eigenart ist dem Menschen sein Dämon». Diese Übersetzung denkt modern, aber nicht griechisch, $\hat{\eta} \theta$ os bedeutet Aufenthalt, 
fundamental de Ethos, no es como se indica usualmente, 'carácter propio’ o 'modo propio' sino estancia, morada (Aufenhalt), lugar del habitar (Ort des Wohnes)". ${ }^{16}$ La ética, entonces, es para Heidegger un habitar (Whonen), y al referirnos al habitar (Whonen) nos estamos refiriendo también al estar-en-elmundo (In-der-Welt-sein), y es que no puede existir el uno sin el otro, el Dasein siempre nos remitirá al mundo (Welt), y éste al Dasein, el estar-en-el-mundo (In-der-Welt-sein) forma parte de la estructura existencial del Dasein, o como Gaos ha traducido, el ser-ahí. El habitar (Whonen) no supone la ocupación de un espacio sino un estar morando, las cosas ocupan espacio, el Dasein mora, y al morar se relaciona con los otros y con las cosas; pero Heidegger señala algo aún más radical, el Dasein sólo puede existir como estar-en-el-mundo (In-der-Weltsein), lo que significa que sólo puede hacerlo habitando. Él es esencialmente un estar-en-el-mundo (Das In-der-Welt-sein) y es como estando-en-el-mundo que las cosas comparecen ante él, no hay otra forma de que esto suceda, y al comprender esto es que el Dasein toma conciencia de su aperturidad (Erschlossenheit) y su vulnerabilidad, se descubre como un ser amenazado; pero también descubre que, hasta cierto punto, él dibuja su mundo. "Pero decir que el mundo es lo que hay y los modos en los que lo que hay está organizado es lo mismo que decir que, en un sentido, el Dasein es el hacedor del mundo, porque es el Dasein quien organiza, ordena, interpreta, etc., el mundo, o más exactamente el mundo ocurre sólo a través del Dasein". ${ }^{17}$

Este estar-en-el-mundo (In-der-Welt-sein) se efectúa en vivencias, ${ }^{18}$ es decir, el Dasein es un ser de carácter ejecutivo, es decir, se encuentra en ejecución constante, la manera que el existe es existiendo, su facticidad (Faktizität) no debe entenderse al estilo positivista, como un hecho, un dato, la facticidad (Faktizität) del Dasein es ejecutiva. Ahora bien, ese estar existiendo se efectúa, tal como señalamos anteriormente, en vivencias, esto es algo radical en Heidegger y lo separa abismalmente de lo que la tradición filosófica había sido antes de él; pero, ¿qué debemos entender por vivencia? Las vivencias no son objetos, no son cosas, aunque esto ciertamente es lo obvio, lo que no es obvio es que las vivencias tampoco son sucesos ni hechos, sino acaecer. ${ }^{19}$

Ort des Whones. Das Wort nennt den offenen Bezirk, worin der Mensch wohnt. Das offene seines Aufenthaltes Lässt das erscheinen, was auf das Wesen des Menschen zukommt und also ankommend in seiner Nähe sich aufhält.”.Heidegger, Martin, Brief über den Humanismus, op.cit. p.17

16. Acevedo Guerra, Jorge, op.cit.

17. Cohn, Priscilla N. Heidegger: su filosofía a través de la nada. Ediciones Guadarrama. Madrid 1975. Pág. 37.

18. "La vivencia (Erlebnis) puede, pues, se considerada como Vorgang, como hecho objetivo. Es esto lo que sucede no sólo en la psicología, sino incluso en la filosofía de Husserl. También a esta se opone Heidegger, como veremos, mediante este concepto de vivencia o de Erlebnis como Ereignis". Villalibre, Modesto Berciano. La revolución filosófica de Martin Heidegger. Editorial Biblioteca Nueva, S.L. Madrid 2001, p. 27.

19. Veáse, Heidegger, Martin. Zur Bestimmung der Philosophie. 
Los hechos ya están consumados, son fijos, estáticos, el acaecer que las vivencias significan es dinámico, es ejecución, y es en ese acaecer en el cual el Dasein se encuentra. La vivencia es el estar existiendo y la realización de posibilidades que se tornan experiencias, experiencias que están en un constante devenir, pero es importante señalar que dichas posibilidades solo lo serán si comparecen como tal en el mundo del Dasein, por lo que no se trata de que las posibilidades sean infinitas tal como piensa el existencialismo de Sartre, sino que son posibilidades en la medida en que un determinado momento histórico permita que comparezcan como tal. Esta última idea es sumamente importante para comprender el sentido de una ética en Heidegger, las posibilidades como se acaba de mencionar no son infinitas, están determinadas por un contexto histórico muy preciso, algo que podríamos llamar un cierto <espíritu epocal.

El Dasein entonces en es un estar-en-el-mundo (In-der-Welt-sein) y está en el mundo arrojado (Geworfenheit), esto es, no ha sido puesto en él, con lo que se rompe cualquier tipo de idea trascendente que recurra a alguna especie de providencia que guíe las acciones del hombre, por lo que el Dasein es responsable de su propio ser y por ende, de todo lo que esto implica, no tiene más opción que habérselas con su mundo, y la implicación más radical, además de ser responsable de su propio ser, nos parece, es que también es responsable del Ser.

“Este carácter de ser del Dasein, oculto en su de-dónde y adónde, pero claramente abierto en sí mismo, es decir, en el 'que es', es lo que llamamos la condición de arrojado [Geworfenheit] de este ente en su Ahí; de modo que en cuanto estaren-el-mundo, el Dasein es el Ahí. El término “condición de arrojado" mienta la facticidad de la entrega a sí mismo. El factum de 'que es y tiene que' abierto en la disposición afectiva del Dasein, no es aquel 'que [es]' que ontológicocategorialmente expresa el carácter de hecho, propio del estar-ahí”. ${ }^{20}$

El Dasein no sólo es un estar-en-el-mundo (In-der-Welt-sein) en condición de arrojado (Geworfenheit) sino también es un poder-ser (Seinkönnen), y ese poder-ser (Seinkönnen) representa su aperturidad (Erschlossenheit).

\section{La Cotidianidad (Alltäglichkeit) del Dasein}

Ciertamente hay mucho que decir sobre el primer Heidegger, específicamente, de Ser y Tiempo (Sein und Zeit), pero debido a que no es la intención de este

20. Heidegger, Martin. Ser y tiempo. Traducción, prólogo y notas de Jorge Eduardo Rivera. Editorial Trotta. Madrid 2003. \$29. Pág. 159. "Diesen in seinem Woher und Wohin verhüllten, aber an ihm selbst um so unverhüllter erschlossenen Seinscharakter des Daseins, dieses »Dass es ist « nennen wir die Gewogenheit dieses Seienden in sein Da, so zwar, dass es als In-der-Welt-sein das Da ist. Der Ausdruck Geworfenheit soll die Faktizität der Überantwortung andeuten. Das in der Befindlichkeit des Daseins erschlossene "Dass es ist und zu sein hat " ist nicht jenes "Dass", das ontologishkategorial die der Vorhandenheit zugehörige Tatsächlichkeit ausdrückt”. Heidegger, Martin, Sein und Zeit, Max Niemeyer Verlag, Tübingen, 2001,\$29, p. 135. 
trabajo ahondar en esa obra, estamos enfatizando sólo aquellos elementos que permitirán comprender mejor el planteamiento que haremos en el último apartado de este trabajo. Dicho lo anterior veamos de forma bastante sucinta cómo ese Dasein que es aperturidad (Erschlossenheit) en su estar-en-el-mundo (In-der-Welt-seins), y que lo es en condición de arrojado (Geworfenheit), enfrenta su cotidianidad (Alltäglichkeit). La forma cotidiana de ser del Dasein es como un estar-caído (Verfallensein) y ser-huyente. El Dasein cae, no de un estado de gracia primigenia, sino de su poder-ser (Seinkönnen), de su aperturidad (Erschlossenheit). Heidegger define la caída (Verfallen) en los siguientes términos:

\begin{abstract}
"Este término no expresa ninguna valoración negativa; su significado es el siguiente: el Dasein está inmediatamente y regularmente en medio del 'mundo' del que se ocupa. Este absorberse en... tiene ordinariamente el carácter de un estar perdido en lo público del uno. Por lo pronto, el Dasein ha desertado siempre de sí mismo en cuanto poder-ser-sí-mismo propio, y ha caído en el 'mundo'. El estado de caída en el 'mundo' designa el absorberse en la convivencia regida por la habladuría, la curiosidad y la ambigüedad". ${ }^{21}$
\end{abstract}

Heidegger nos ha aclarado entonces que la caída (Verfallen) no es más que un absorberse en el Uno (Das man). Este Uno (Das man) son los otros, es decir, todos, pero ninguno. ¿Qué significa esto?, que el Uno (Das man) es el plano del "se" impersonal, del "se dice", "se hace", "se vende", pero quién dice, quién vende, quién hace, es algo que no podemos precisar; sin embargo es un alguien o un algo que dicta nuestra pautas de comportamiento, nuestras creencias, nuestras posibilidades nuestra interpretación de mundo (Welttanschauung), nuestros valores, y por ende, nuestras acciones.

En vista del propósito de nuestro trabajo, debemos enfatizar en uno de los efectos que esta cotidianidad (Alltäglichkeit) cadente del Dasein tiene porque se encuentra en estrecha relación con un posible planteamiento ético, dicho efecto es el alivianamiento (Entlastung). Este consiste en la liberación de cualquier tipo de asunción de responsabilidad de parte del Dasein por alguna acción realizada, ya que al estar en la permanente escucha del Das man en su cotidianidad, todas las pautas de conducta, todo aquello que se nos presenta como posible o imposible nos es señalado por el Uno, por el "se". Sin embargo, ese "se" es completamente indefinido, no podemos precisar quién es ni a dónde está, pero nos libera de cualquier tipo de responsabilidad ya que es él quien

21. Ibid. §38. Pág 198. "Der Titel der keine negative Bewertung ausdrückt, soll bedeuten: das Dasein ist zunächst und zumeist bei der besorgten »Welt «. Dieses Aufgehen bei... hat meist den Charakter des Verlorenseins in die Öffentlichkeit des Man. Das Dasein ist von ihm selbst als eigentlichem Selbstseinkönnen zunächst immer schon abgefallen und an die »Welt« verfallen. Die Verfallenheit an die »Welt« meint das Aufgehen im Miteinandersein, sofern dieses durch Gerede, Neugier und Zweideutigkeit geführt wird”. Heidegger, Martin, Sein und Zeit, op.cit,\$38, p. 175. 
nos dicta qué hacer, por lo tanto, él es el responsable de las acciones y no el Dasein mismo. "Así el uno aliviana al Dasein en su cotidianidad. Pero no sólo eso; con este alivianamiento del ser, el uno satisface los requerimientos del Dasein, en tanto que en éste se da la tendencia a tomar todo a la ligera y a hacer las cosas en forma fácil. Y puesto que el uno con el alivianamiento del ser satisface constantemente los requerimientos del Dasein, mantiene y refuerza su porfiado dominio". ${ }^{22}$ El Dasein entonces, en la caída (Verfallen), cae de su ser más propio, de sus posibilidades y se hunde en la cotidianidad (Alltäglichkeit) donde es el Das man quien dicta las regulaciones de la existencia, existencia que por ser cadente, es impropia o inauténtica.

\section{Ser-para-la-muerte (Das Sein zum Tode) como fundante de una ética}

Llegados a este punto estamos en el momento álgido de nuestro trabajo, el título de este último apartado es bastante sugerente, pero además, puede ser considerado como un tanto transgresor al intentar cualificar al ser-para-lamuerte (Das Sein zum Tode) como punto de partida de una ética en Heidegger. En lo que resta de nuestra investigación trataremos de dar cuenta de esta tesis que ha dirigido nuestro trabajo y que aún está sujeta a una mayor investigación. Por el momento la presentamos como una tesis que guiará futuras investigaciones. El Dasein al ser un ser fáctico comparte el destino de todo lo fáctico, de todo lo viviente, a saber, la muerte. Sin embargo, en sentido estricto, sólo el Dasein muere, porque la muerte, entendida no como un hecho sino como una posibilidad, sólo es propia del Dasein, ya que la muerte implica la conciencia de su advenimiento, cosa que los demás vivientes no poseen. Los animales y las plantas simplemente llegan a su fin existentivo. La muerte revela al Dasein su propia contingencia y su finitud, la inminencia (Bevorstand) lo enfrenta a la conciencia de la temporalidad y del fin de ésta. Y de la misma manera que existen dos formas en las cuales el Dasein existe, a saber, propiedad (Eigentlichkeit) e impropiedad (Uneigentlichkeit), así también hay dos formas de habérselas con la muerte que dependerá del tipo de existencia en que el Dasein se encuentre. La existencia impropia vive absorbida en el uno, el "se" impersonal, la muerte no comparece ante el Dasein porque este tipo de existencia la oculta, huye de ella, mientras que en la existencia propia hay una asunción de ella y ésta se torna en un existenciario, y al tornarse un existenciario, el Dasein se torna un ser-para-la-muerte (Sein zum Tode).

La muerte es así no sólo el límite de la facticidad, y por consiguiente de la temporalidad, sino también, es el fin de las posibilidades.

“Los mortales son los hombres. Se llaman mortales porque pueden morir. Morir

22. Ibid. §27. Pág. 152. "Das Man entlastet so das jeweilige Dasein in seiner Altäglichkeit. Nicht nur das; mit dieser Seinsentlastung kommt das Man dem Dasein entgegen, sofern in diesem die Tendenz zum Leichtnehmen und Leichtmachen liegt. Und weil das Man mit der Seinsentlastung dem jeweiligen Dasein ständig entgegenkommt, behält es und verfestigt es seine hartnäckige Herrschaft”. Heidegger, Martin, Sein und Zeit, op.cit.\$27, pp. 127-128. 
quiere decir ser capaz de la muerte en cuanto muerte. Sólo el hombre muere, el animal termina. No tiene a la muerte como muerte ni delante ni detrás de él. La muerte es el cofre de la nada, es decir, de aquello que desde ningún punto de vista es algo que simplemente es, pero que, a pesar de todo, esencia, incluso como el misterio del ser mismo. La muerte, como cofre de la nada, alberga en sí, lo esenciante del ser. La muerte, como el cofre de la nada es el albergue del ser. A los mortales les llamamos ahora los mortales, no porque su vida terrena termine, sino porque son capaces de la muerte como muerte. Los mortales son los que son como los mortales, esenciado en el albergue del ser. Ellos son la relación esenciante con el ser como ser". ${ }^{23}$

El Dasein es un ser ejecutivo, un ser posible, un poder-ser (Seinkönnen), pero sólo lo es precisamente porque es un ser temporal, lo que significa un ser que muere. Muerte y temporalidad van de la mano, sólo se muere porque se es temporal, y sólo se es temporal porque se muere, pero esto que pudiese parecer algo completamente negativo no lo es, la muerte es la que hace posible la posibilidad que somos, si no muriésemos no seríamos seres posibles, seres en construcción, sino todo lo contrario, seríamos dioses y por lo tanto seres de realidad. Todo en nosotros sería pura realidad, no cabría ni la más mínima posibilidad de que hubiese posibilidad. El poder-ser (Seinkönnen) que la muerte y la temporalidad permiten, y con ello, ciertamente la irrupción de lo histórico, es un aún-no y un haber-pasado. El Dasein es aquellas posibilidades que ya ha efectuado, haber-pasado, y también es aquello que aún no se ha realizado, un aún-no, esto último significa que el Dasein está en un constante anticiparse-así, y esto es un carácter fuerte de futuridad en él. "Si el Dasein es proyecto se realiza como tal anticipando sus posibilidades futuras que, al moverse dentro de la finitud, deben anticipar la propia muerte como posibilitante último de ese horizonte. El Dasein se reconoce como ente aparte porque es el único capaz de desbordar el presente, capaz de 'pre-ser-se' anticipando su futuro y capaz de saber anticipadamente que va a morir”. ${ }^{24}$ El Dasein no está en el tiempo ni en la historia, tampoco es un ser que va hacia la muerte, él es tiempo, es historia y es muerte, tampoco se trata de que cada día que el Dasein vive sea al mismo tiempo un día de muerte, esto implicaría ser un ser-muriente, la muerte es una

23. Heidegger, Martin, “La cosa”, en, Filosofía, ciencia y técnica, traducción Francisco Soler, Editorial universitaria, Santiago de Chile, 2007, p. 251. "Die Sterblichen sind die Menschen. Sie heissen die Sterblichen, weil sie sterben Können. Sterben heisst: den Tod als Tod vermögen. Nur der Mensa stirbt. Das Tier verendet. Es hat den Tod als Tod weder vor sich noch hinter sich. Der Tod ist der Schrein des Nichts, dessen nämlich, was in aller Hinsicht niemals etwas bloss Seiendes ist, was aber gleichwohl west, sogar als das Geheimnis des Seins selbst. Der Tod birgt als der Schrein des Nichts das Wesende des Seins in sich. Der Tod ist als Schrein des Nichts das Gebirge des Seins. Die Sterblichen nennen wir jetzt die Sterblichen - nicht, weil ihr irdisches Leben endet, sondern weil sie den Tod als Tod vermögen. Die Sterblichen sind, die sie sind, als die Sterblichen, wesend im Gebirg des Seins. Sie sind das weisende Verhältnis zum Sein als Sein”. Heidegger, Martin, Das ding, en, Vorträge und Aufsätze, Band 7, Gesamtausgabe, Vittorio Klostermann, Frankfurt Am Main, 2000, p. 180.

24. Ramos, Antonio Pintor. Historia de la Filosofía Contemporánea. Biblioteca de Autores Cristianos. Madrid, 2002, p. 243. 
posibilidad en cuanto es un aun-no, es la máxima posibilidad del Dasein, y como posibilidad es algo que forma parte constitutiva de su existencia.

La conciencia de la muerte nos hace tomar conciencia también de nuestra propia contingencia y finitud, por lo que, al menos en principio, debería de hacernos sentir responsables de nuestras acciones y del ser. El Dasein existe en el claro del ser, existe, o debería existir pensando la verdad del ser. Por ello, precisamente, es que dentro del planteamiento heideggeriano la ética debe ser comprendida desde el pensamiento del filósofo de la selva negra y no desde el exterior, porque la ética obedecería a la crítica, al despliegue y a la búsqueda que Heidegger realiza. Para nuestro autor el desarrollo de su pensamiento es algo que está fuera, completamente, de lo que ha significado el desarrollo de occidente, para él, su pensamiento ya no es filosofía. La filosofía comienza con Platón y termina con Nietzsche, su pensamiento es un pensamiento originario y al igual que en el caso de los pre-socráticos, la ética forma parte de él, pero no existe separada como una disciplina. "Ético es el pensamiento filosófico, pero el 'otro pensamiento' post-filosófico no puede ya serlo, del mismo modo como no lo fue tampoco el pensar presocrático. El fin de la filosofía es al mismo tiempo el fin de la ética". ${ }^{25}$

Heidegger no habla de ética ni de valores porque estos ya están implícitos en su pensar originario y forman parte de una ética originaria ${ }^{26}$, desde esta perspectiva, su planteamiento es avalórico; pero lo es porque el pensamiento hegemónico continúa siendo el metafísico, por lo tanto, los valores expuestos en él obedecen a esa filosofía que Heidegger ha acusado del olvido del ser en reiteradas ocasiones, sin embargo, debe comprenderse que Heidegger dista mucho de ser alguien inmoral o inhumano.

Resumiendo, la valoración heideggeriana de la ética pasa por una consideración histórica y épocal de la misma, de allí que para nuestro autor la ética sea producto del despliegue metafísico occidental que es un despliegue cadente que ha olvidado al Ser y además -en la actualidad-obedece a un pensar calculador (Das Rechnende Denken), un pensar hegemónico que valora en términos de medición o de cálculo, de costo-beneficio, perdida-ganancia, un pensar donde hasta el objeto (Gegenstand) ha dejado de serlo para advenir un constante (Bestand), unas existencias constantes (Bestände) siempre disponibles. Ahora queda más claro, nos parece, el por qué Heidegger no escribió una ética y el sentido del carácter avalórico de su pensamiento, aunque algunos autores, como por ejemplo Jean Grondin, ven en la distinción heideggeriana de 'autenticidad' e 'inautenticidad' una suerte de interpretación normativa que desembocaría en

25. Pirard, Eduardo Carrasco. "Heidegger y la Ética”. Depto. De Filosofía. Universidad de Chile, Visto en, https://es.scribd.com/doc/253538430/Heidegger-y-La-Etica-Eduardo-Carrasco-Pirard.

26. Hay algunos autores como Barbara Merker que hablan incluso de una ética fenomenológica en el pensamiento heideggeriano. Veáse, Selbsttäuschung und Selbterkenntnis, Zu Heideggers Transformation der Phänomenologie Husserl, Frankfort del Meno, Suhrkamp, 1998. 
una crítica de la configuración actual de las sociedades. ${ }^{27}$ Siendo consecuente con su pensamiento y con la búsqueda de esa experiencia originaria que vio en Grecia, específicamente en los pre-socráticos, Heidegger aboga por una suspensión del juicio, y con ello, una destrucción de los valores metafísicos presentes en las valoraciones éticas, para, de esta manera volver a ese vínculo esencial con el $\mathrm{Ser}^{28}$, de ahí que parta de una ética negativa ${ }^{29}$, en contra posición con la afirmativa que ha caracterizado a Occidente. En La Carta sobre el Humanismo (Brief über den Humanismus) lo reitera en diversas ocasiones a lo largo de todo el escrito. Ser y Tiempo (Sein und Zeit) es el inicio de este pensar originario, y por lo tanto, también está dentro de este pensar que pretende alejarse de los aspectos valóricos occidentales, el caso concreto es la muerte misma. Desde el pensamiento metafísico la muerte posee un sentido porque hay un ente trascendente que la dota de él, y es sólo desde esta trascendencia que la muerte es principio de vida. En el planteamiento del mago de Messkirch la muerte siempre está presente a lo largo de toda la existencia humana, y es ella la que nos hace ser seres posibles, proyectos, seres históricos, así, la muerte vuelca al Dasein hacia el exterior, siendo en este sentido un sobrepasamiento (Überstieg); pero no refiere que el Dasein esté volcado hacia un ente fuera de este mundo que dé a la muerte sentido y significado, sino más bien, a la muerte como algo de carácter inmanente, por lo que ésta podría comprenderse como una trascendencia inmanente.

"Ante la "Hybris" del siglo XX, y ante la ceguera de toda esta época de desenfrenado optimismo y confianza en los poderes de dominio humano, quizás podamos ser capaces algún día de aprender con Heidegger, esa piedad que es el pensar, sin salir del recinto en que impera la tensión de unidad de contrarios, formada, por un lado, por la extrema indigencia humana, y por el otro, por el extremo poder del ser. Allí donde según el antiguo anunciado de Parménides,

27. Cfr., García Ruíz, Pedro Enrique, "Humanismo y subjetividad. Heidegger y desfondamiento ontológico de la ética", en, Anuario de Filosofía, Vol. 1, Universidada Autónoma de méxico UNAM, México, 2007, pp. 135-136.

28. Cfr., Holzapfel, Cristóbal, “El pensamiento a-valórico heideggeriano”, en, Aventura ética. Hacia una ética originaria, Universidad de Chile, visto en, http://padron.entretemas.com/cursos/ Antologia/RecursosEpistemMetod/DiccionariosGlosariosAntologias/Nietzsche/personales.ciudad. com.ar/M_Heidegger/holzapfel.htm

29. Según el Profesor y Dr. Cristobal Holzapfel de la Universidad de Chile -en su libro, Aventura ética. Hacia una ética originaria editado por Lom Ediciones en coedición con la Facultad de Filosofía y Humanidades de la Universidad de Chile- puede hablarse de dos tipos de ética, “(...) podemos plantear una distinción entre dos tipos de ética, a las que llamaremos ética afirmativa y ética negativa. Respecto de la primera, cabe decir que toda ética es en primer lugar afirmativa, si entendemos por ésta la propuesta de una escala calórica determinada que arroja asimismo criterios para valorar las más distintas situaciones que nos tocan enfrentar, permitiéndonos de este modo una orientación existencial. Indudablemente que la ética socrático-platónica, la ética aristotélica, la ética cristiana, la ética kantiana se presentan con esos perfiles. Ellas representan, podríamos decir, la gran avenida de la ética occidental. Pero hay también la clara posibilidad de una ética negativa. En ésta se trataría de una disposición al retiro de las valoraciones (...) se deja ver que la ética negativa no se aplica tanto a las escalas valóricas propuestas en la tradición, sino sobre todo a las valoraciones que se hacen a partir de ellas". 
ser y pensar, son lo mismo, allí también tiene el prodigio de que la libertad y el destino sean lo mismo". ${ }^{30}$

\section{Conclusiones}

El ser-para-la-muerte (Das Sein zum Tode) conduce al Dasein a encontrarse con aquello que es esencial en la existencia humana, a saber, el habitar (Wohnen). La ética es para Heidegger un habitar (Wohnen), pero, ¿qué debemos entender por habitar? El filósofo de la selva negra nos responde en Bauen Wohnen Denken de 1951, "Habitar, ser llevado a la paz, significa: permanecer circundado en lo Frye, esto es en lo Freie [libre], que protege a todo en su esencia. El rasgo fundamental del habitar es este proteger". ${ }^{31}$ El habitar (Wohnen) es proteger (Schonen), pero, ¿qué debe proteger el Dasein?

"Los mortales habitan de manera que ellos protegen lo cuadrante en su esencia. Según eso, el proteger habitante es cuádruple. Los mortales habitan en cuanto salvan la tierra... Salvar la tierra es más que sacarle provecho o, pues, trabajarla excesivamente. El salvar a la Tierra no domina a la Tierra y no hace esclava a la Tierra, de donde sólo hay un paso hasta la explotación sin límites. Los mortales habitan en cuanto acogen el cielo en cuanto cielo... no convierten la noche en día y el día en fatiga llena de ajetreos. Los mortales habitan en cuanto esperan a los divinos en cuanto divinos". 32

La ética es un habitar (Wohnen); pero no de cualquier modo, ese habitar (Wohnen) es un proteger (Shonen) desde lo cuadrante (das Geviert). La muerte (Tod) es el origen de esta manera de habitar protegiente.

"Los mortales habitan en cuanto que a su propia esencia, que es tener el poder de la muerte en cuanto muerte, la conducen hacia el uso de ese poder para que sea buena muerte. Los mortales guiados hacia la esencia de la muerte no significa, de ningún modo, poner como meta la muerte en cuanto vacía nada; tampoco mienta el entenebrecer el habitar por medio de un ciego poner la vista en el fin. En el salvar a la tierra, en el acoger al Cielo, en el esperar a los

30. Ibidem.

31. Heidegger. Martin, "Construir Habitar Pensar", en Filosofía ciencia y técnica, Prólogo de Francisco Soler y Jorge Acevedo, Editorial Universitaria, Santiago de Chile, 2007, p. 212. "Wohnen, zum Frieden gebracht sein, heisst: eingefriedet bleiben in das Frye, d.h. in das Freie, das jegliches in sein Wesen schont. Der Grundzug des Wohnens ist dieses Schonen". Heidegger, Martin, "Bauen Wohnen Denken”, en, Vorträge und Aufsätze, Gesamtausgabe, Vittorio Klostermann, Frankfurt am Main, 2000, p. 151.

32. Heidegger Martin, "Construir Habitar Pensar" ibid p. 214. "Die Sterblichen wohnen in der Weise, dass sie das Geviert in sein Wesen schonen. Demgemäss ist das wohnende Schonen Verfältig. Die Sterblichen wohnen, insofern sie die Erde retten... Die Erde retten ist mehr, als sie ausnützen oder gar abmühen Das Retten der Erde meistert die Erde nicht und macht sich die Erde nicht untertan, von wo nur ein Schritt ist zur schrankenlosen Ausbeutung. Die Sterblichen wohnen, insofern sie den Himmel als Himmel empfangen... sie machen die Nacht nicht zum Tag und den Tag nicht zur gehetzten Unrast. Die Sterblichen wohnen, insofern sie die Göttlichen als die Göttlichen erwarte". Heidegger. Martin, ibid. p. 152. 
Divinos, en el guiar de los mortales, se acontece el habitar en cuanto cuádruple proteger de lo cuadrante". ${ }^{33}$

La muerte (Tod) es un no-lugar, es el espacio de lo indecible, aquello a lo cual sólo podemos asistir porque cuando enfrentamos nuestra propia muerte y llegamos así a nuestro estar-entero es imposible que podamos dar cuenta de ella, así, la muerte es aquello que no tiene fundamento. Es un abismo (Abgrund) que escapa del afán representativo de nuestro lenguaje. La muerte es silenciamiento (Still), es un fondo en el que el Dasein cobra sentido como un ser mortal, como un poder-ser (Seinkönnen) y cuyo modo de ser se ve condicionado. El Dasein habita el mundo; pero lo habita desde su carácter de ser-ejecutivo, desde su aperturidad (Erschlossenheit), ese proteger cuádruple que es el habitar (Wohnen) sólo es posible porque el Dasein es un ser abierto, un ser que se construye constantemente a sí mismo y a ese mundo que habita, y es abierto y ser de posibilidades porque es un ser-para-la-muerte (Das Sein zum Tode).

\section{Bibliografía}

\section{a) Textos fuente}

Heidegger, Martin, Filosofía, ciencia y técnica, Prólogo de Francisco Soler y Jorge Acevedo, Editorial Universitaria, Santiago de Chile, 2007.

Heidegger, Martin, Vorträge und Aufsätze, Vittorio Klosterman, Frankfurt am main, 2000. Heidegger, Martin, Ser y tiempo, Traducción, prólogo y notas por Jorge Eduardo Rivera,

Ed. Trotta, Madrid, 2003.

Heidegger, Martin, Sein und Zeit, Max Niemeyer Verlag, Tübingen.

Heidegger, Martin, Beiträge zur Philosophie (Vom Ereignis), Vittorio Klosterman, Frankfurt am main, 2003.

Heidegger, Martin, Contribuciones a la Filosofía (Del acontecimiento), Traducción de Breno Onetto Muñoz, Traducción presentada como proyecto de investigación postdoctoral, 1999-2002, Chile.

\section{b) Textos complementarios}

Cohn, Priscilla, Heidegger, su filosofía a través de la nada, Ediciones Guadarrama, Madrid,1975.

Acevedo Guerra, Jorge, Heidegger: existir en la era técnica, Ediciones Universidad Diego Portales, Santiago de Chile, 2014.

Basso Monteverde, Mercedes Leticia, Génesis y constitución del Ereignis. Un estudio de la

33. Heidegger. Martin, Ibid. pp. 214, 215. "Die Sterblichen wohnen, insofern sie ihr eigenes Wesen, dass sie nämlich den Tod als Tod vermögen, in den Brauch dieses Vermögens geleiten, damit ein guter Tod sei. Die Sterblichen in das Wesen des Todes geleiten, bedeutet keineswegs, den Tod als das leere Nichts zum Ziel setzen; es meint auch nicht, das Wohnen durch ein blindes Starren auf das Ende verdüstern”. Heidegger, Martin, Ibid. pp. 152,153. 
continuidad de la obra de Martin Heidegger [1919-1939] a través del problema de la diferencia ontológica, Tesis para optar al grado de Doctora en Filosofía, UBA, Argentina, 2013.

Villalibre, Modesto Berciano, La revolución filosófica de Martin Heidegger, Editorial Biblioteca Nueva, Madrid, 2001.

Ramos, Antonio Pintor, Historia de la Filosofía Contemporánea, Biblioteca de Autores Cristianos, Madrid, 2002.

\section{c) Revistas}

Acevedo Guerra, Jorge, “Ética originaria y la psiquiatría”, en, Observaciones Filosóficas, Revista digital, 2006, visto en http://www.observacionesfilosoficas.net/ eticaoriginaria.html

Volpi, Franco, “¿Es posible aún una ética? Heidegger y la Filosofía práctica”, en, Konvergencias, Filosofía y Culturas en Diálogo, Número 7 Año III Agosto/ Septiembre, Argentina, 2004, visto en, http://www.konvergencias.net/volpi.htm

Pirard, Eduardo Carrasco. Heidegger y la Ética. Depto. De Filosofía. Universidad de Chile, visto en, http://www.heideggeriana.com.ar/comentarios/carrasco.htm

Escudero, Adrián Jesús, “Ser y tiempo: ¿una ética del cuidado?”, en, Aurora № 13, 2012.

Di Silvestre, Carlos, “La temporeidad extático-horizontal como origen de la trascendencia del Dasein”, en, Discusiones Filosóficas, Año 11 № 17, julio-diciembre, Colombia, 2010, pp. 255-273.

García Ruíz, Pedro Enrique, “Humanismo y subjetividad. Heidegger y desfondamiento ontológico de la ética”, en, Anuario de Filosofía, Vol. 1, Universidad Autónoma de México UNAM, México, 2007.

Holzapfel, Cristóbal, “El pensamiento a-valórico heideggeriano”, en, Aventura ética. Hacia una ética originaria, Universidad de Chile, visto en, http://padron.entretemas. com/cursos/Antologia/RecursosEpistemMetod/DiccionariosGlosariosAntologias/ Nietzsche/personales.ciudad.com.ar/M_Heidegger/holzapfel.htm

\section{d) Linkografia}

Heidegger, Martin. Carta sobre el Humanismo, p. 17, visto en, http://www.sandamaso. es/uploaded_files/3_heidegger_carta_sobre_el_humanismo.pdf

Heidegger, Martin, Brief über den Humanismus, visto en, http://www.sandamaso.es/ uploaded_files/3_heidegger_carta_sobre_el_humanismo.pdf 